\title{
Importance of source apportionment modeling in air pollution abatement policy
}

\author{
Vinod Kumar Sharma
}

Published online: 29 December 2009

(C) Springer-Verlag 2009

Air pollution problems, particularly in the emerging economies, are endangering the health and welfare of people. Both ambient and indoor air pollution levels have reached an alarming stage in the developing countries. Major sources of ambient air pollution are industries, power plants, and motor vehicles emitting the high levels of Oxides of Sulfur $\left(\mathrm{SO}_{\mathrm{x}}\right)$, Oxides of Nitrogen $\left(\mathrm{NO}_{\mathrm{x}}\right)$, Carbon Monoxide (CO), Suspended Particulate Matter (SPM), Hydro Carbons (HC), and numerous other pollutants. On the other hand, high level of indoor air pollution is the result of low quality fuels such as wood, coal, and kerosene, etc., that are being used in rural and urban poor households. Several studies have shown that the levels of SPM, NOx, and HC are resulting in higher incidences of respiratory diseases like tuberculosis, cardiovascular diseases, and asthma. In addition to the health hazards, air pollution also has several other detrimental effects such as reduction in visibility, spoiling of buildings, damage to material and machines, and ill effects on vegetation and animals (Hopke 1988; Okamoto et al. 1990; Sharma and Patil 1992, 1994; Sharma 2007).

While the sources of the most gaseous pollutants are well defined, it is difficult to identify the origin of particulate pollutants. Even if it is possible to identify the major sources of such pollutants, qualitatively, their quantitative contributions may not be ascertained by the policy makers. As the decision makers are not sure of the share of pollution from various contributing sources in an area, they can not use any policy measure focusing on a particular source or a group of sources. Thus, implementation of a pollution

V. K. Sharma $(\bowtie)$

Indira Gandhi Institute of Development Research (IGIDR),

Filmcity Road, Goregaon (East), Mumbai 400065, India

e-mail: vks@igidr.ac.in abatement policy without identifying the real culprit, i.e., the major pollution source(s) in an area becomes difficult. In such a situation, the site specific source apportionment techniques could act as the management and decisionmaking tools.

Source Apportionment Modeling (SAM) techniques are basically statistical methods, which essentially use a chemical mass balance equation. The main assumption of these techniques is that the pollutants do not transform, physically or chemically, during their transport from the source to the receptor. For example, the amount of total lead $(\mathrm{Pb})$ arriving at a receptor will be the linear sum of the lead emitted by all sources of lead surrounding the receptor, say, lead from automobiles, lead from an incinerator, etc.,

$\mathrm{Pb}($ Total $)=\mathrm{Pb}($ Auto $)+\mathrm{Pb}($ Incinerator $)+\cdots \cdots \cdot$

However, the lead emitted from any source, say, Auto, is a fraction of the total emissions from Auto,

$\mathrm{Pb}($ Auto $)=\mathrm{a}(\mathrm{Pb}) * \mathrm{f}($ Auto $)$

In the generalized form, it can be expressed as

$C_{\mathrm{i}}=\sum A_{\mathrm{ij}} * S_{\mathrm{j}}$

where, $C_{\mathrm{i}}$ is the concentration of species " $\mathrm{i}$ " from "P" number of sources

$A_{\mathrm{ij}}$ is the fraction of the species " $\mathrm{i}$ " from source $\mathrm{j}$

$S_{\mathrm{j}}$ is the source strength of source " $\mathrm{j}$ "

This set of variables are used in the Chemical Mass Balance $(\mathrm{CMB})$ Model, represented by-

$C_{\mathrm{i}}=\sum X_{\mathrm{ij}} * M_{\mathrm{j}}$

where, $X_{\mathrm{ij}}$ and $M_{\mathrm{j}}$ correspond to $A_{\mathrm{ij}}$ and $S_{\mathrm{j}}$ in Eq. 1, respectively.

Thus, in the CMB, Observed Concentration is the Linear Combination of Source Strength $\mathrm{Mj}$. 
Equation 2 is a set of linear simultaneous equations, which could be solved by the commonly used Least Square Method.

The application of SAM in an area, with unknown sources of air pollution, requires collection of ambient air pollution data such as concentration level of SPM and gaseous pollutants. The results of the SAM are based on the abundance of marker species of pollution indicating the presence of a particular source in the area of concern. Thus, the knowledge and experience of the modeler about the presence of major sources of pollution plays an important role while selecting sources and their marker species. The concentration of these maker species is determined through a sophisticated laboratory analysis. The ambient pollution data and makers' species provide a set of variables, which are used in a statistical analysis such as CMB or factor analysis and multiple regression, to get a source apportionment, i.e., the quantitative contribution of each source to the receptor.

An example of the final results, using CMB model are given in the Fig. 1. Suppose a modeler, with his experience and knowledge of the area identifies, say, seven sources (S1, S2 ...S7), the percentage contribution from these sources, using the CMB model, will be obtained as, P1, P2 .......P7, respectively, as shown in the Fig. 1. It is to be noted that it is never possible to apportion $100 \%$ of the pollution in any area, and therefore, always an unknown percentage (PU) of pollution will be contributed by an unknown sources (SU), as shown in the Fig. 1.

In the above figure, contribution from Sources S1, S2, and S3 is much higher than the rest of the sources, and hence, it is desirable to focus pollution abatement measures on these sources. Thus, the results of the SAM could guide various stakeholders including the researcher and policy

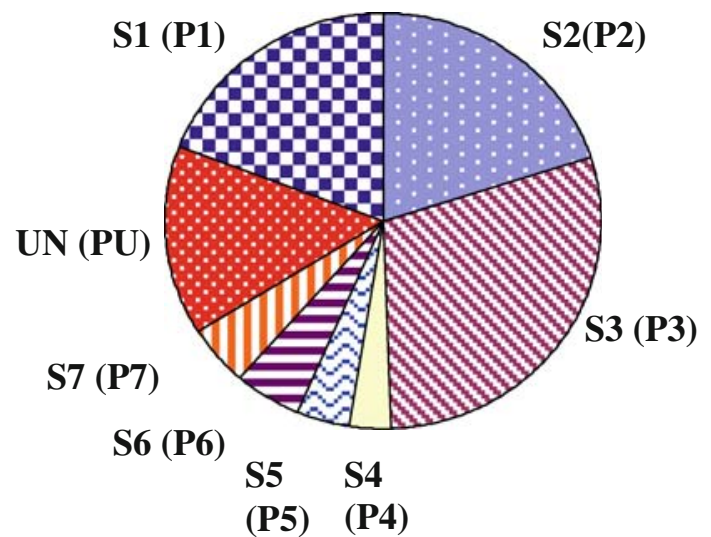

Fig. 1 Source contribution by CMB

makers in implementing a suitable pollution abatement policy in the area of concern.

\section{References}

Hopke PK (1988) Target transformtion factor analysis as an aerosol mass apportionment. Atmos Environ 22(9):1777-1792

Okamoto S et al (1990) A factor analysis-multiple regression model for source apportionment if suspended particulate matter. Atmos Environ 24A(8):2089-2097

Sharma VK (ed) (2007) Maharashtra state development report, a major policy document on prepared for the planning commission, Govt. of India. Oxford University Press, New Delhi

Sharma VK, Patil RS (1992) Size distribution of atmospheric aerosols and their source identification using factor analysis in Bombay, India. Atmos Environ 26B(1):135-140

Sharma VK, Patil RS (1994) Chemical mass balance model for source apportionment of aerosols. Environ Monit Assess 29(1):75-88 